\title{
Multiple Treatment Meta-Analysis of Products Evaluated for Control of Fire Blight in the Eastern United States
}

\author{
H. K. Ngugi, B. L. Lehman, and L. V. Madden
}

First and second authors: Department of Plant Pathology, Pennsylvania State University, Fruit Research and Extension Center, Biglerville 17307; and third author: Department of Plant Pathology, The Ohio State University, Ohio Agricultural Research and Experimental Center, Wooster 44961.

Accepted for publication 16 December 2010.

\begin{abstract}
Ngugi, H. K., Lehman, B. L., and Madden, L. V. 2011. Multiple treatment meta-analysis of products evaluated for control of fire blight in the eastern United States. Phytopathology 101:512-522.

The aim of this analysis was to estimate the effect sizes and consistency of products evaluated for fire blight control in the eastern United States over the last decade. Because only $3 \%$ of the 69 studies published from 2000 to 2008 explicitly presented a measure of within-study variability, a method for estimating the least significant difference (LSD) and, hence the sampling variance, for studies with at least two significant mean separations in the presented mean multiple comparisons was developed. Lin's concordance analysis indicated that the estimated LSD was an accurate predictor of the actual LSD based on 35 studies in a calibration evaluation $\left(\rho_{c}=0.997\right)$. Separate multi-treatment random-effects metaanalyses were performed for three control categories: antibiotics, biological control, and plant defense-activating products and mean log response ratios relative to the nontreated controls $(\bar{L})$ were computed for

provided the best fire blight control with mean effect sizes ranging from 59.7 to $61.7 \%$. Among the biological controls, the best control was noted for treatments combining the antibiotic streptomycin with a product based on Pantoea agglomerans (55.0\% mean disease reduction) or Bacillus subtilis (53.9\%). Mean disease control was 31.9, 25.7, and $22.6 \%$, respectively, for products based on B. subtilis, Pantoea agglomerans, and Pseudomonas fluorescens without an antibiotic, suggesting that the higher efficacy of the combination treatments was due to the antibiotic. Among the plant defense-activating products, prohexadione calcium had the highest and most consistent effect size (50.7\% control), while other products provided modest mean disease control of between 6.1 and $25.8 \%$. Percent control values were significantly moderated by study location and cultivar used in the study, and were smaller, but more variable, when products were tested under high disease intensity compared with low disease intensity. Results indicate that wide-scale use of biological control and plant defense-activating products in the eastern United States is likely to remain low.
\end{abstract} each treatment and then back-transformed to obtain the mean percent disease control. None of the products evaluated performed as well as streptomycin, the standard product for fire blight control, for which the mean disease control was $68.6 \%$. As a group, experimental antibiotics
Additional keywords: Erwinia amylovora, flower biology, systemic acquired resistance.
Fire blight, caused by Erwinia amylovora (Burrill) Winslow et al., is the most destructive bacterial disease of apples and pears worldwide $(51,53)$. The disease, which was first described in the early 19th century in the United States, remains a major constraint to apple production in the eastern United States. The incidence and severity of fire blight in commercial apple orchards has increased over the last 25 years owing to increased cultivation of highly susceptible cultivars grafted on susceptible dwarfing rootstock $(6,29,53)$. Driven largely by this increased disease intensity and potential losses expected from severe epidemics, the development of resistance to the antibiotic streptomycin — the mainstay chemical for control - in the western United States, Michigan (23), and New York (42), and the ever present risk of streptomycin withdraw (24), the search for alternative products for fire blight management has remained sustained.

Fire blight has a complex disease cycle consisting of canker blight, blossom blight, shoot blight, trauma blight, and rootstock blight $(29,49,51)$. However, blossom blight and shoot blight stages cause the most obvious disease symptoms. Under typical

Corresponding author: H. K. Ngugi; E-mail address: hkn3@psu.edu

* The $e$-Xtra logo stands for "electronic extra" and indicates that the online version contains one supplemental document.

doi:10.1094/PHYTO-08-10-0221

(C) 2011 The American Phytopathological Society orchard conditions, secondary spread of E. amylovora is primarily by insect transmission during pollination and the potential for disease spread is highest during bloom period $(15,35,49,51)$. Once inside the host tissue, E. amylovora becomes systemic within the vascular tissue thereby limiting the effectiveness of control products most of which have a contact mode of action. These factors make it imperative to control the blossom blight phase of fire blight to prevent systemic shoot infections $(6,51)$. Moreover, the blossom blight phase of fire blight is short-lived and the risk of infection can be predicted using forecasting systems $(2,6)$. Not surprisingly, most of the products evaluated for fire blight control have focused on blossom protection $(16,36,51)$.

A wide range of products with different modes of action have been evaluated for control of fire blight in the United States over the last 10 years. However, there are conflicting reports about the effectiveness of these products especially when results obtained in the eastern United States are compared with studies carried out in the west coast apple production regions. For example, several labeled biological control products that are apparently effective in the west coast have not provided consistent fire blight control in the eastern United States $(4,26,47)$. Moreover, qualitative reviews of many of the products evaluated for fire blight control worldwide indicate highly variable levels of product efficacy $(36,51)$. There is a need, therefore, to assess the effectiveness and consistency of the products evaluated for fire blight control and to formulate informed hypotheses about any inconsistency. 
Recent attempts to assess product efficacy for fire blight control have been limited to comparisons among treatments within individual studies (26,56-58), and narrative summaries of results across studies in the eastern United States that focused on biocontrol products $(4,47)$. In these qualitative research syntheses, conclusions were drawn based on simple averages of disease control by individual treatments across studies as well as counts of the number of studies in which a given treatment had provided a significant $(P<0.05)$ result relative to a nontreated check. No attempts were made to account for inherent differences among studies that likely influenced the magnitude and precision of the treatment effects. Although generally informative, qualitative research synthesis can result in misleading conclusions. For example, syntheses based merely on tallies of studies with significant $P$ values have been shown to lead to totally erroneous conclusions $(12,14,21)$. Moreover, qualitative summaries cannot effectively model the effects of moderator variables that affect the size and variability of the estimated mean effect sizes. By contrast, quantitative research synthesis, otherwise referred to as meta-analysis, provides an excellent alternative to qualitative reviews for integrating and interpreting results from multiple individual studies $(14,20,21,41,55)$. Mean effect sizes for some of the biocontrol agents used against E. amylovora were computed by Ojiambo and Scherm (31). However, that meta-analysis addressed the broader questions of biological- and applicationrelated factors that influence the effectiveness of biocontrol agents in general without focusing on any disease. The objectives of this review were to (i) determine the effect sizes of products evaluated for fire blight control in the eastern United States over the last 10 years; (ii) determine and explain the consistency or inconsistency associated with the effect sizes; and (iii) identify factors affecting the efficacy of the products evaluated. An additional objective was to develop a method for estimating withinstudy variability to allow synthesis of studies that do not report such statistics.

\section{MATERIALS AND METHODS}

Product efficacy database. A database of efficacy trials of products evaluated for fire blight control was extracted from the Fungicide \& Nematicide Tests (F\&N Tests), Biological \& Cultural Tests (B\&C Tests), and Plant Disease Management Reports (PDMR) which replaced the F\&N and B\&C Tests reports from 2007. For the remainder of this paper, these sources will collectively be referred to as PDMR for clarity. These sources were used because they publish disparate reports of product evaluation studies regardless of whether the results are positive, i.e. statistically significant, or negative (31). A search of these databases was carried out using the keywords "fire blight" and "Erwinia amylovora" and all the resulting studies were screened to determine eligibility for inclusion in the meta-analysis. All studies were included except those failing to meet the following criteria. Firstly, a study had to have a measure of disease (incidence or severity), or an index that could be computed to one of these measures of disease intensity. Secondly, the study had to be replicated and to include a nontreated control. Thirdly, the study should have been carried out in the eastern United States, hereby defined as the region on continental United States to the east of the Rocky Mountains, between 1999 and 2007 and therefore included in the PDMR between 2000 and 2008. The reason for this criterion was that initially the analysis was limited to biocontrol products for which anecdotal evidence suggested efficacy was much higher in the region to the west of the Rocky Mountains.

Out of the 69 studies retrieved by the search, the products tested could be broadly grouped into three categories based on the type of the active ingredient or its mode of action. The three broad categories are as follows. (i) Antibiotics (streptomycin sulfate, gentamicin, kasugamycin and oxolinic acid). Streptomycin, which was applied as the commercial product Agri-strep, Agri-mycin, Firewall, or BacMaster, is labeled for fire blight control in the United States and was used in all reports as the standard treatment. Oxytetracycline, which was applied as Mycoshield or Flameout, received supplemental registration for fire blight in 2010. The other antibiotics were experimental products. Copper products were also included among the antibiotics based on the general biocide activity of copper ions which are the active ingredients. (ii) Biological control products included in this study were applied as formulations of Bacillus subtilis, Pantoea agglomerans, and Pseudomonas fluorescens. (iii) Plant defense-activating compounds. Treatments grouped together as plant defense activators were comprised of diverse products, including the gibberellic acid inhibitor prohexadione-calcium (Apogee), the harpin protein (Messenger), acibenzolar-S-methyl (Actigard), a plant defense elicitor extracted from brown algae (Physpe 4, also known as Vacciplant), phosphorous acidcontaining products (Nutri-Phite, ProPhyt, Phostrol [Phosphites]), and the plant growth stimulating product Vigor-cal [Nutrient]). The exact mode of action for some of these products is not well understood.

The number of products evaluated per study also varied substantially but all of the studies included contained at least two treatments; a nontreated control and the standard streptomycin treatment. In some studies, various treatment combinations consisting of application times and rates were reported. In such cases, only the treatments applied at the same time as the standard treatment were included in the meta-analysis. Where multiple application rates were evaluated, only the treatments consisting of manufacturer recommended rates were included in the analysis. In the few cases where multiple rates were tested and the recommended rate could not be determined, a mean effect for treatments containing the same compound was computed. Two studies were dropped from the analysis because the measure of fire blight severity used (area under disease progress curves) was not compatible with that used in rest of the studies.

Initially, the criteria also included a requirement for studies to have an estimate of pooled sample variance $(V)$, or a statistic that would permit direct calculation of $V$ (such as the least significant difference [LSD]). However, this condition was dropped when it became apparent that $>97 \%$ of the reports did not directly supply $V$ or a related statistic. The pooled sampling variance is the residual mean square from analysis of variance for a study. However, most PDMR do not report this statistic but often include other statistics such as Fisher's protected LSD from which $V$ can be computed. For the two studies that reported Fisher's protected LSD, the variance $V$ was calculated based on the formula

$$
V=\frac{n \cdot(L S D / 1.96)^{2}}{2}
$$

$(20,32)$, where $n$ is the number of replicates of each treatment in the study (usually four or five). Most PDMR indicate mean separation based on multiple comparisons (a function of the LSD). Thus, these studies provide an indirect measure of variability and hence $V$. For studies with mean separations, a method for obtaining an estimate of $V$ based first on deriving the LSD for studies meeting certain criteria was developed and is outlined below. For those studies for which the LSD could be estimated based on this method, the within-study variance $(V)$ was then computed based on equation 1 by replacing LSD with the estimated LSD (ELSD).

Method for estimating LSD. This method was based on the premise that when a study reported a significant mean separation based on other multiple comparison tests, the same separation would have been obtained using Fisher's protected LSD which is the least conservative among the commonly used multiple com- 
parison tests (39). By definition, for any study with a significant mean separation within a collection of means, the actual value of the LSD is greater than the largest nonsignificant difference between the means but smaller than the smallest significant difference. This method therefore could only be computed for studies that had at least one significant mean separation. The estimate of the LSD was computed by determining for the collection of means, the smallest observed significant difference, and the largest observed nonsignificant difference between the means, and averaging between these two values.

As a very simple example, consider the case of three means with two significant separations presented as follows:

$\begin{array}{cc}\text { Treatment } 1 & 5 \mathrm{a} \\ \text { Treatment } 2 & 10 \mathrm{a} \\ \text { Treatment } 3 & 18 \mathrm{~b}\end{array}$

Because the first two means are not significantly different, the LSD must be greater than 5 (i.e., $10-5$ ). However, because the third mean is significantly different from the second, the LSD must be less than $8(18-10)$. Thus, $5<$ LSD $\leq 8$. The average of these two values gives the ELSD. Obviously the accuracy of the estimate will increase with number of treatments, the number of nonsignificant treatment differences, and the number of significant treatment differences.

To test the robustness of this method, we used data from 35 fungicide testing trials carried out at the Pennsylvania State University Fruit Research and Extension Center over the last 10 years. These trials were designed to evaluate fungicides for control of apple diseases (J. W. Travis, personal communication) and most of the data have been published in PDMR, but were not included in the present meta-analysis. For these 35 studies, the LSD value was obtained using the GLM procedure of SAS (SAS Institute Inc., Cary, NC). We then calculated the ELSD as outlined above based on the letter display of mean separations. The accuracy, at which the ELSD values predicted actual LSD values was determined with Lin's concordance analysis (18). A concordance correlation coefficient $\left(\rho_{c}\right)$ measures the variation of data from the line of concordance (or unity) which is a line with a slope of 1 and a zero intercept. The concordance coefficient is the product of Pearson's correlation coefficient $(r)$, which is a measure of the precision (variability), with which the ELSD values estimated the actual LSD, and a coefficient of bias $\left(C_{b}\right)$ which is a measure of the closeness of the best-fitting line to the concordance line.

Statistical synthesis of product efficacy. Effect size estimates. Fire blight severity in PDMRs is often reported as a mean percentage of infected clusters out of the total of those assessed in a given treatment. For each treatment within a given study, the mean levels of disease in treated and control plots were used to compute the effect size. In preliminary analyses, the response ratio $(R)$ was computed for each treatment as described by Paul et al. (32) and Hedges, et al. (11). Typically, when $R$ is used as the effect size, a meta-analysis of a single treatment arm is based on the natural $\log$ transformation $(L)$ of the response ratio, because $L$ has several advantages over $R(11,21,32)$. However, because most studies tested multiple treatments, there were several response values for each study, each corresponding to one of the treatments (products or combination of products) evaluated relative to the control. Multivariate random effects meta-analyses were, therefore, performed for each of the data sets representing control groups as described in Paul et al. (33) and van Houwelingen et al. (52). To avoid functional correlations between effect sizes within a given study arising from a common denominator (mean of control treatment) when computing $R$, the analyses were based on $\log$ mean response of treatments in each study $(11,33)$. Mean response ratios across all studies could then be estimated using the modeling approach below.
In keeping with Paul et al. (33), the multivariate random effects model fitted was

$$
\boldsymbol{Y}_{i} \sim N\left(\boldsymbol{\mu}, \Sigma+\boldsymbol{S}_{i}\right)
$$

where $\boldsymbol{Y}_{i}$ is a vector of responses over the $K$ studies $(i=1, \ldots K)$ for which a normal distribution with a mean $\mu$ and a variancecovariance matrix $\Sigma+S_{i}$ was assumed. For example, the response vector $\boldsymbol{Y}_{i}$ for the $i$ th study that evaluated six antibiotics, gentamicin, kasugamycin, oxytetracycline, oxolinic acid, copper, and streptomycin, and a nontreated control was specified as

$$
Y_{i}=\left(\begin{array}{l}
\ln \left(\bar{X}_{\text {Gent }}\right) \\
\ln \left(\bar{X}_{\text {Kasa }}\right) \\
\ln \left(\bar{X}_{\text {Oxyt }}\right) \\
\ln \left(\bar{X}_{\text {Oxol }}\right) \\
\ln \left(\bar{X}_{\text {Copp }}\right) \\
\ln \left(\bar{X}_{\text {Strep }}\right) \\
\ln \left(\bar{X}_{\text {Cont }}\right)
\end{array}\right)=\left(\begin{array}{c}
Y_{\text {Gent }} \\
Y_{\text {Kasa }} \\
Y_{\text {Oxyt }} \\
Y_{\text {Oxol }} \\
Y_{\text {Copp }} \\
Y_{\text {Strep }} \\
Y_{\text {Cont }}
\end{array}\right)
$$

where $\bar{X}_{j}$ is the mean response (i.e., disease intensity defined as percentage of diseased clusters, or other measurement), for treatment $j$ ( $j=$ gentamicin, kasugamycin, oxytetracycline, oxolinic acid, copper, streptomycin, or nontreated control in study $i$ ). The within-study variance-covariance matrix, $\boldsymbol{S}_{i}$ consists of the variance for the $\log$ responses for each treatment as the diagonal element, and zero for the off-diagonal elements. For instance, for the $j$ th treatment of a single study, the within-study variance is estimated as $S_{j}^{2}=V /\left(n \bar{X}_{j}^{2}\right)$, where $V$ is the residual error component of the study. In most cases, $V$ is estimated based on the LSD method described above (equation 1), and $n$ is the number of replicates in the study (usually 4 or 5 ). $\Sigma$ is the between-study variance-covariance matrix, which characterizes the variability among the studies of the treatment log means.

The mean response $\boldsymbol{Y}_{i}$ evaluated across $K$ studies is given by $\boldsymbol{\mu}$ (33). In the case of the six antibiotics evaluated and the control, the elements of $\boldsymbol{\mu}$ are given by the mean response (on a log scale) for the specific treatments:

$$
\mu=\left(\begin{array}{l}
\mu_{\text {Gent }} \\
\mu_{\text {Kasu }} \\
\mu_{\text {Oxyt }} \\
\mu_{\text {Oxol }} \\
\mu_{\text {Copp }} \\
\mu_{\text {Strep }} \\
\mu_{\text {Cont }}
\end{array}\right)
$$

A similar approach was used to formulate models for data from studies representing the other product categories (biological control and plant defense-activating compounds). In each case, estimates of the mean effect size $(\boldsymbol{\mu})$ and the variance-covariance matrix $(\Sigma)$ for each treatment were obtained by fitting equation 2 to the data using the maximum likelihood method with the MIXED procedure in SAS (SAS Institute Inc.; van Houwelingen et al. [52]). Note that, under this method each treatment does not have to be evaluated across all studies.

To assess the suitability of a random-effects model for the analysis, a fixed-effect meta-analysis model was also fitted to the data to determine if there was significant between-study variability. The fixed-effect model is the same as the model in equation 2 , but with 0 for the elements of the between-study matrix $\Sigma$; i.e., the between-study variance is not estimated. To determine the magnitude and impact of the among-study variability on the mean effect sizes and their confidence intervals, the $R^{2}$ statistic of Higgins and Thompson (13) was calculated as $R^{2}=\left(\mathrm{SE}_{\mathrm{Ran}} / \mathrm{SE}_{\mathrm{Fix}}\right)^{2}$, 
where $S E_{\mathrm{Ran}}$ and $S E_{\mathrm{Fix}}$ refer to the standard error of the estimated mean effect for a given treatment under the random effects and fixed effect models, respectively. $R^{2}$ describes the inflation of the random-effects confidence interval for the effect size relative to that from a fixed-effect model (13), and is not a coefficient of determination computed in regression analyses.

The differences of two estimated means (on the log scale), is the same as the estimated $\log$ ratio $\bar{L}=\ln (\bar{R})$ (33). This is because the difference in logs is identical to the log of a ratio. As an example, the estimated log response ratio for streptomycin relative to the control is $\bar{L}=\hat{\mu}_{\text {Strep }}-\hat{\mu}_{\text {Cont }}$. The estimated response ratio is given by $\bar{R}=\exp (\bar{L})$. Differences in log means, and hence response ratios, were restricted to each treatment and the nontreated control. The mean percent control (i.e., disease reduction relative to the control) was estimated as $\bar{C}=(1-\bar{R}) \cdot 100$. Confidence limits for $\bar{C}$ were obtained by back-transforming the limits of the $95 \%$ confidence intervals for $\bar{L}$ values $(32,33)$.

The efficacies of products tested for fire blight control were evaluated based on the magnitude and significance of $(\bar{L})$ and ( $\bar{C}$ ). High negative values of $\bar{L}$ convert into higher positive values of $\bar{C}$, i.e., more effective disease control. The confidence intervals show the magnitude of the variation of the effect size and could be used to test whether or not the treatment significantly affected the log response. That is, if the limits of the confidence intervals for $\bar{L}$ were below 0 (meaning that $\bar{L}$ was significantly less than 0 , the same as $\bar{R}<1$, or $\bar{C}>0$ ), then the treatment had an effect. A standard normal test $Z=\bar{L} / S E_{(\bar{L})}$ also shows the significance of the treatment effect (32).

Moderator variables. Several categorical variables describing ecological or study-specific properties were defined and used to assess the effects of the factors in each of the three product category data sets. The categorical variables evaluated were as follows: (i) the apple cultivar on which the test was performed; (ii) state in which the test was carried out; and (iii) level of disease intensity in the test based on the level of fire blight in the nontreated plots. Disease intensity was defined as a binary variable by classifying disease level as "low" in studies that reported disease severity less than $65 \%$ in the control plots, or "high" when disease level in the control plot was $\geq 65 \%$. The $65 \%$ cut-off was chosen based on median values of disease level in control plots for each of the three data sets (data not shown). The multivariate random effects model was expanded to assess the effects the moderator variables as described in Paul et al. (33). The model including the moderator variable as a covariate was specified as

$$
Y_{i} \sim N\left(\mu+\delta_{i}, \Sigma+S_{i}\right)
$$

where $\delta_{i}$ is a vector defining the effects of the moderator variable on the response vector, and all other parameters are as defined previously (33). A separate meta-analysis was completed for each moderator variable for each of the three product category data sets. For all meta-analyses, the effects of the moderator variables were assessed based on Wald $\chi^{2}$ statistics of type III tests of fixed effects. Estimates of means of the log responses for treatments under different levels of moderator variables were obtained with "estimate" statements of the MIXED procedure (SAS Institute Inc.). Percent disease control and 95\% confidence limits for the treatments at each level of the moderator variable were computed as described for the analyses without moderator variables.

\section{RESULTS}

Database of products evaluated for fire blight control in the eastern United States. The PDMR databases contained 69 studies published from 2000 to 2008 that had evaluated products for fire blight control. The number of studies varied from year to year ranging from five studies in 2000 and 2004 to a high of 12 in
2006, and annual average of approximately eight studies. The number of products/compounds tested in these studies was also variable, but with an apparent increasing trend over time. Most of the studies were carried out in one of five states to the east of the Rocky Mountains, namely New York (22\% of the studies), Michigan (18\%), Virginia (22\%), Pennsylvania (17\%), and North Carolina (13\%), which may reflect the size of the apple industry in the states.

Method for estimating LSD. The number of significant mean separations in the 35 studies used for developing the method for estimating LSD ranged from 2 to 7, with five separations being most common. Based on these 35 calibrator studies, the Lin's concordance coefficient $\left(\rho_{c}\right)$ between "estimated" and "actual" LSD was 0.9968 , which is almost equal to the perfect coefficient of 1 (Fig. 1). Moreover, there was hardly any disagreement between the line of concordance and the best linear regression line obtained for the two variables $\left(C_{b}=0.9999\right.$, where a value of 1 is considered perfect; i.e., that the best fitting regression line is equal to the line of concordance). Pearson's product correlation coefficient, a measure of the precision along the best-fitting line was 0.9969 ( $n=35 ; P<0.0001$; Fig. 1$)$.

Although the minimum number of significant mean separations required to estimate the LSD was one, the precision of the estimate was low for studies with only one separation (H. K. Ngugi, unpublished data). Based on this consideration, an additional three studies were dropped from the meta-analysis data set because an estimate of the within-study variance could not be computed as there were insufficient mean separations to allow an accurate estimation of the LSD.

Fire blight intensity in the studies. The products evaluated could be placed in one of three categories based on the type of active ingredient; antibiotics, biological control products, and products designed to activate plant defense mechanisms such as the systemic acquired resistance (SAR). Based on the mean level of disease in nontreated plots, fire blight intensity levels varied substantially between studies, but the overall level of disease was generally similar for studies in the three product categories. Mean fire blight severity levels in nontreated plots ranged from 2.5 to $95 \%$ in studies evaluating antibiotics, 1.2 to $95 \%$ for studies

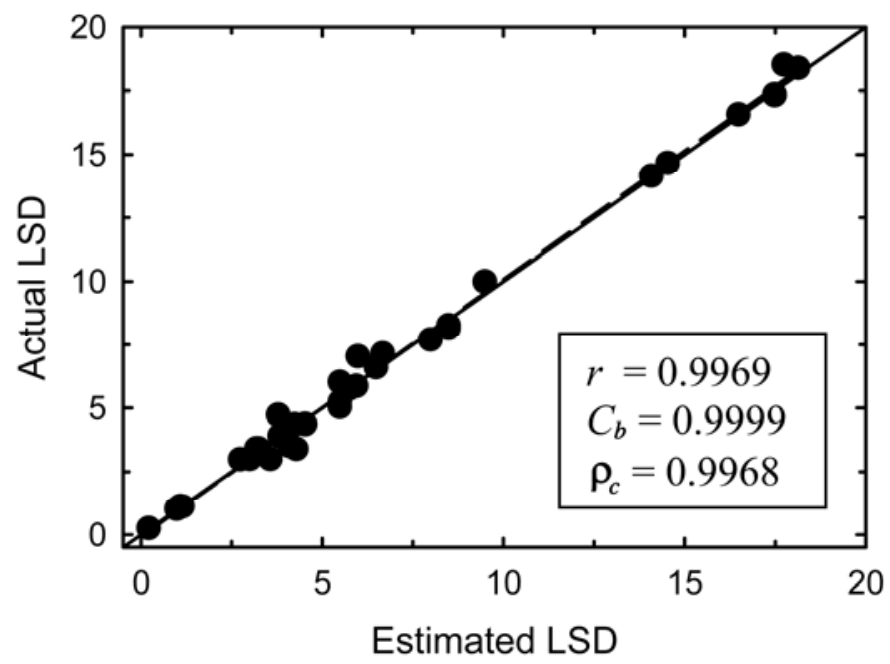

Fig. 1. Relationship between estimated and actual least significant difference (LSD) values for 35 data sets of fungicide trials used to evaluate the accuracy of a method for estimating LSD values based on mean separations reported in typical Plant Disease Management Reports. The solid line is the concordance line indicating a perfect agreement between actual and estimated LSD values. The broken line is the best-fitting regression for the data. The accuracy with which estimated LSD reproduces the actual LSD was assessed with Lin's concordance correlation $\left(\rho_{c}\right)(18)$, calculated as the product of the Pearson's product correlation coefficient $(r)$, and the bias correlation factor $\left(C_{b}\right.$; where $1=$ no bias, i.e., perfect relationship). 
evaluating biological control products, and 2.5 to $95 \%$ in studies evaluating plant defense-activating compounds. The median levels of fire blight in these data were $61.4,64.1$, and $60.8 \%$ for studies evaluating antibiotics, biological control products and plant defense-activating compounds, respectively. The coefficient of variation values for fire blight levels in the nontreated control plots were $52.9,51.9$, and $56.7 \%$, respectively, for studies evaluating antibiotics, biological control products and plant defenseactivating compounds.

Effect sizes and product efficacy for fire blight control. The response ratios $(R)$ computed at the individual study level for the antibiotic products ranged from 0 to 1.25 (Fig. 2). By contrast, values of response ratios ranged from 0 to 1.43 , and from 0 to 1.44 , for biocontrol products and the plant defense-activating products, respectively. Values of $R$ above 1 indicate that the treat-
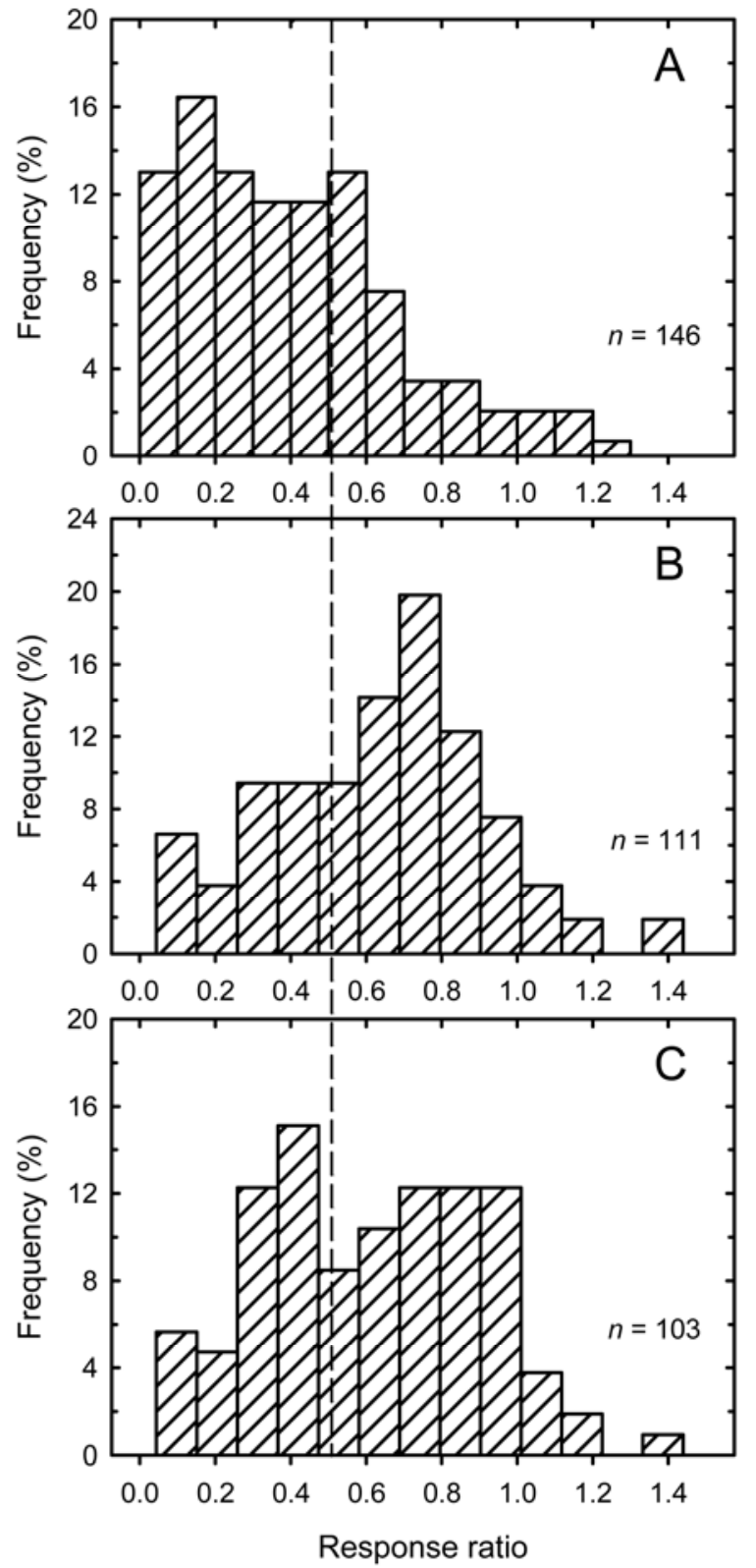

Fig. 2. Frequency distributions of response ratios for $\mathbf{A}$, antibiotic products, $\mathbf{B}$, biological control products, and $\mathbf{C}$, plant defense-activating products, evaluated for control of fire blight on apples in the eastern United States between 1999 and 2007. The distributions are based on the total number of treatments (n) evaluated across all studies, with the number of treatments varying between individual studies. Response ratio values to the left of the broken line $(R=0.5)$ indicate disease level in plots receiving the treatment was less than half that in the nontreated control. ment had a higher mean disease level than the control. Overall, only $37.2 \%$ of the response ratios for antibiotics were $>0.5$, compared with $65.1 \%$ for biological control agents and $60.4 \%$ for plant defense-activating products (Fig. 2). Values of $R>0.5$ indicate that mean fire blight level in the treatment plot was more than $50 \%$ of that in the nontreated control. Tests for normality indicated that $R$ values in each of the three categories did not follow normal distribution based on Shapiro-Wilk test for normality $(0.945 \leq W \leq 0.971 ; P<0.0001$, for data including $R$ values for streptomycin in all categories) thus justifying, in part, computing effect sizes based on $L$, the natural log-transformation of $R$, through the use of equation 2 .

Assessment of between-study heterogeneity. Values of the $R^{2}$ statistic (13) ranged from 1.36 to 7.9 across the meta-analyses for the three product categories (Tables 1 to 3 ). Except for studies used to estimate the mean effect size for streptomycin, the $R^{2}$ statistics values were $>1.65$ for all mean effect sizes, and greater than 3 in a majority of the cases (Tables 1 to 3 ). Higgins and Thompson (13) showed that values of $R^{2}$ above 1.5 indicate heterogeneity has considerable impact on the estimates of mean effect size and its confidence interval. Based on this outcome, meta-analytical models with nonzero random-effects were used for all the analyses.

Product efficacy comparisons. Of all the products evaluated, those based on streptomycin sulfate provided the best disease control, with $\bar{L}$ values ranging from -1.12 to -1.20 , depending on the product category meta-analysis (Tables 1 to 3 ). For all the antibiotics evaluated, the $\bar{L}$ values were significantly different from zero based on the standard normal test $(4.62 \leq Z \leq 12.58$; $P<0.0001$; Table 1$)$. Similarly, the $\bar{L}$ values were significantly different from 0 for all treatments consisting of biological control products, although $\bar{L}$ values and their corresponding test statistics $(Z)$ were generally lower than those obtained for the antibiotics (Table 2). Among the plant defense-activating products, the estimates of $\bar{L}$ were also significantly different from 0 for all treatments except Vacciplant $(\bar{L}=-0.062 ; P=0.332)$ and Actigard ( $\bar{L}=-0.186 ; P=0.213$ ) (Table 3 ).

Among the antibiotics, most experimental products performed with a relatively similar level of efficacy, with mean percent disease control ranging from $59.8 \%$ for products based on oxolinic acid to $61.7 \%$ for oxytetracycline products, with values for gentamicin and kasugamycin being intermediate (Table 1). Copper based products, which although not antibiotics were included in this product category, had a mean control of only $37.6 \%$ disease control (Table 1). Values of the mean disease control estimated for streptomycin, across the three product category meta-analyses were $69.8 \%, 95 \%$ confidence interval [CI] 61.3 to $73.7 \%$ for antibiotics, $68.9 \% \mathrm{CI}=57.3$ to $72.3 \%$ for biocontrol products, and $67.3 \% \mathrm{CI}=60.2$ to $73.1 \%$, for defenseactivating products (Tables 1 to 3 ). When the products in the antibiotics category were evaluated relative to the streptomycin sulfate standard, only copper was significantly poorer than streptomycin with a mean difference in disease reduction of $32 \%(P<$ 0.0001 ; Table 1). Oxytetracycline, the only other antibiotic with a U.S. registration for fire blight control, averaged about $8.1 \%(P=$ $0.054)$ lower disease control than the streptomycin based-products (Table 1).

Except for a treatment combining products based on $P$. fluorescens and $P$. agglomerans, all other biocontrol treatments significantly reduced $(P \leq 0.01)$ fire blight relative to the nontreated control (Table 2). However, the effect sizes of most of the biological control products relative to nontreated control were significantly smaller compared with that of streptomycin. The exception to this were treatments that combined the biocontrol products with streptomycin, for which the mean disease control was $>41 \%$ (Table 2 ). The best control was noted for treatments combining streptomycin with a product based on $P$. agglomerans ( $\bar{L}=-0.797 ; Z=-5.48 ; P<0.0001$, equating to $\bar{C}=55.0 \%$ ) or 
Bacillus subtilis $(\bar{L}=-0.773 ; Z=-7.63 ; P<0.0001 ; \bar{C}=$ $53.9 \%$; Table 2). Indeed, the effect size for the treatment combining streptomycin and P. agglomerans was not statistically smaller $(P=0.131)$ than that for streptomycin alone. It should be noted that neither of these combination treatments performed significantly better than streptomycin. When evaluated as sole products, the largest effect size was obtained for products based on B. subtilis ( $\bar{L}=-0.385 ; Z=-4.62 ; P<0.0001$; Table 2 ). This value translated to a modest $31 \%$ mean disease control over the nontreated control. The poorest performance was noted for products based on $P$. fluorescens, with a mean disease control of $22 \%$ (Table 2).

The effect sizes of plant defense activators evaluated as sole products relative to nontreated control varied considerably, from a high of $\bar{L}=-0.593$ ( $\bar{C}=38.5 \%$ ) for phosphite compounds, to a low of $\bar{L}=-0.062(\bar{C}=6.1 \%)$ for Vacciplant (Table 3$)$. The $R^{2}$ statistics ranged from 1.85 to 7.9 indicating considerable variation among studies (Table 3). The gibberellic acid inhibitor prohexadion-calcium (Apogee), had a mean effect size of -0.707 , (i.e., $50.7 \%$ disease reduction over the nontreated check) (Table $3)$. The $\bar{L}$ for Actigard (-0.186) and Vacciplant (-0.062) were not significantly different from zero (Table 3 ). These two treatments also had the highest values of the $R^{2}$ statistic (7.9 and 5.7 for
Actigard and Vacciplant, respectively). However, treatments consisting of these products used in combination with streptomycin performed as well as the antibiotic; mean disease control was 67.4 and $65.5 \%$ for the streptomycin-Actigard and streptomycinVacciplant combination treatments, respectively (Table 3).

Influence of moderator variables. The effect sizes (log response ratios) were significantly $\left(4.30 \leq \chi^{2} \leq 226.48 ; 0.0001 \leq\right.$ $P \leq 0.0381)$ affected by the cultivar on which the products were tested, disease intensity in the study, the state in which the study was carried out, as well as whether the product was used in a combination program with the antibiotic streptomycin (Table 4). Based on the linear contrasts between the levels of the moderator variables, only effects sizes for studies carried out in Georgia and North Carolina were significantly different $(P<0.0001)$ from those of the other states across the three meta-analyses (data not shown). Overall, treatments were less effective when tested in the southern states (Georgia and North Carolina) than when evaluated in the northern states (Michigan, New York, Pennsylvania, and Virginia).

Across the three meta-analyses, treatments generally had lower and more variable effect sizes ( $\bar{L}$ values and corresponding $\bar{C}$ values) when tested under high disease intensity compared with low disease intensity. Among the antibiotics, the effects sizes of

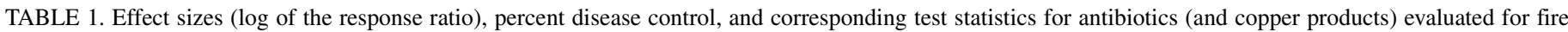

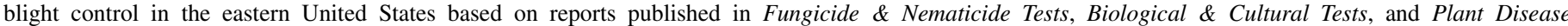
Management Reports between 2000 and 2008

\begin{tabular}{|c|c|c|c|c|c|c|c|c|c|c|c|}
\hline \multirow[b]{2}{*}{ Antibiotic } & \multirow[b]{2}{*}{$K^{\mathrm{a}}$} & \multirow[b]{2}{*}{$R^{2 \mathrm{~b}}$} & \multicolumn{6}{|c|}{ Effect size ${ }^{c}$} & \multicolumn{3}{|c|}{ Mean disease control $(\%)^{\mathrm{d}}$} \\
\hline & & & $\bar{L}$ & $S E_{\bar{L}}$ & $\mathrm{CI}_{L}$ & $\mathrm{CI}_{U}$ & $Z$ & $P$ & Control $(\bar{C})$ & $\mathrm{CI}_{L}$ & $\mathrm{CI}_{U}$ \\
\hline Streptomycin & 61 & 1.46 & -1.197 & 0.104 & -1.401 & -0.993 & -11.61 & $<0.0001$ & 69.79 & 61.34 & 73.73 \\
\hline Gentamicin & 21 & 1.65 & -0.945 & 0.136 & -1.211 & -0.679 & -6.96 & $<0.0001$ & 61.13 & 49.27 & 70.21 \\
\hline Kasugamycin & 9 & 3.75 & -0.907 & 0.196 & -1.291 & -0.522 & -4.62 & $<0.0001$ & 59.61 & 40.64 & 72.51 \\
\hline Oxytetracycline & 8 & 2.42 & -0.960 & 0.076 & -1.110 & -0.810 & -12.58 & $<0.0001$ & 61.70 & 55.52 & 67.03 \\
\hline Oxolinic acid & 9 & 2.17 & -0.911 & 0.143 & -1.192 & -0.630 & -6.36 & $<0.0001$ & 59.77 & 46.71 & 69.63 \\
\hline Copper products & 23 & 1.95 & -0.471 & 0.091 & -0.650 & -0.293 & -5.19 & $<0.0001$ & 37.59 & 25.40 & 47.78 \\
\hline
\end{tabular}

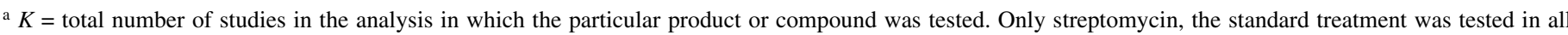
studies analyzed.

${ }^{\mathrm{b}} R^{2}$ describes the inflation of the random effects confidence interval (CI) for the effect size compared with that from a fixed effects model (13).

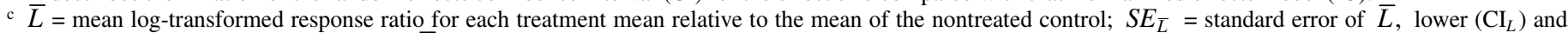
upper $\left(\mathrm{CI}_{U}\right)$ limits of the $95 \% \mathrm{CI}$ around $\bar{L}$; and $Z$ (standard normal) statistic from the meta-analysis. $P=$ probability value (significance of the effect size).

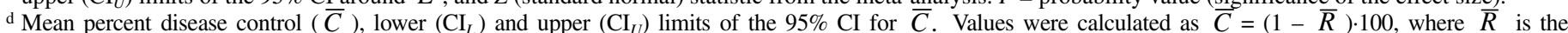
mean response ratio or confidence limit estimate. Values of $\bar{R}$ and the confidence limit estimates were obtained by back-transforming $\bar{L}$ values and the confidence limits for $\bar{L}$.

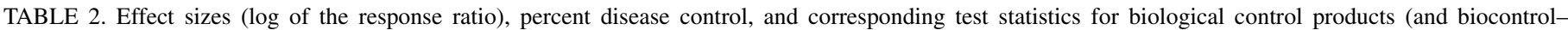

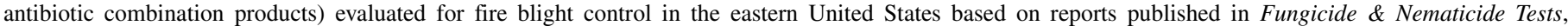
Biological \& Cultural Tests, and Plant Disease Management Reports between 2000 and 2008

\begin{tabular}{|c|c|c|c|c|c|c|c|c|c|c|c|}
\hline \multirow[b]{2}{*}{ Product based on ${ }^{\mathrm{a}}$} & \multirow[b]{2}{*}{$K^{\mathrm{b}}$} & \multirow[b]{2}{*}{$R^{2 \mathrm{c}}$} & \multicolumn{6}{|c|}{ Effect size ${ }^{d}$} & \multicolumn{3}{|c|}{ Mean disease control $(\%)^{\mathrm{e}}$} \\
\hline & & & $\bar{L}$ & $S E_{\bar{L}}$ & $\mathrm{CI}_{L}$ & $\mathrm{CI}_{U}$ & $Z$ & $P$ & Control $(\bar{C})$ & $\mathrm{CI}_{L}$ & $\mathrm{CI}_{U}$ \\
\hline Streptomycin & 57 & 2.62 & -1.168 & 0.110 & -1.285 & -0.852 & -9.69 & $<0.0001$ & 68.91 & 57.34 & 72.32 \\
\hline Bacillus subtilis & 24 & 4.30 & -0.385 & 0.148 & -0.975 & -0.394 & -4.62 & $<0.0001$ & 31.93 & 32.57 & 62.29 \\
\hline Pantoea agglomerans & 10 & 3.59 & -0.298 & 0.083 & -0.460 & -0.135 & -3.60 & 0.0003 & 25.73 & 12.65 & 36.86 \\
\hline Pseudomonas fluorescens & 18 & 3.64 & -0.257 & 0.102 & -0.456 & -0.057 & -2.52 & 0.0119 & 22.62 & 5.52 & 36.64 \\
\hline P. fluorescens $+P$. agglomerans & 6 & 3.67 & -0.163 & 0.097 & -0.352 & 0.027 & -1.68 & 0.0932 & 15.01 & -2.76 & 29.70 \\
\hline Streptomycin $+B$. subtilis & 19 & 3.03 & -0.773 & 0.101 & -0.972 & -0.574 & -7.63 & $<0.0001$ & 53.86 & 43.70 & 62.18 \\
\hline Streptomycin $+P$. agglomerans & 11 & 1.81 & -0.797 & 0.146 & -1.083 & -0.512 & -5.48 & $<0.0001$ & 54.95 & 40.05 & 66.14 \\
\hline Streptomycin $+P$. fluorescens & 8 & 1.99 & -0.544 & 0.104 & -0.749 & -0.339 & -5.21 & $<0.0001$ & 41.97 & 28.78 & 52.72 \\
\hline
\end{tabular}

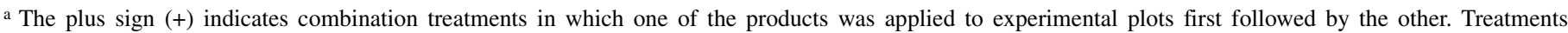
consisting of the same pair of test products were combined regardless of the sequential order in which the two products were applied in the test $(P$. fluorescens + P. agglomerans, Streptomycin + B. subtilis, Streptomycin + P. agglomerans, or Streptomycin + P. fluorescens).

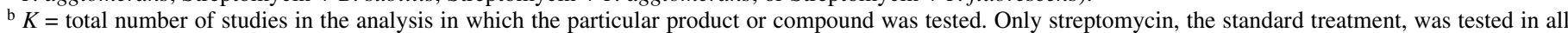
studies analyzed.

${ }^{\mathrm{c}} R^{2}$ describes the inflation of the random effects confidence interval (CI) for the effect size compared with that from a fixed effects model (13).

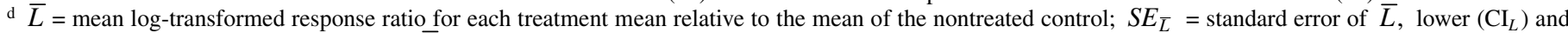
upper $\left(\mathrm{CI}_{U}\right)$ limits of the $95 \% \mathrm{CI}$ around $\bar{L}$; and $Z$ (standard normal) statistic from the meta-analysis. $P=$ probability value (significance of the effect size).

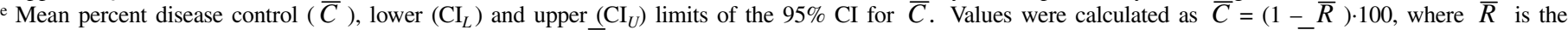
mean response ratio or confidence limit estimate. Values of $\bar{R}$ and the confidence limit estimates were obtained by back-transforming $\bar{L}$ values and the confidence limits for $\bar{L}$. 
all the experimental antibiotics, except oxolinic acid, were not significantly different from zero when the products were tested under high disease intensity (Fig. 3A). The effect sizes for kasugamycin were the most highly variable, with mean percent disease control estimated as $9.5 \%$ (CI: -15.5 to $34.5 \%$; i.e., $P=$ 0.7282 ), and $56.8 \%$ (CI: 33.8 to $77.9 ; P=0.0013$ ) under high and low disease intensity, respectively (Fig. 3A). Streptomycin provided the most consistent performance regardless of disease intensity during the tests, and its effect sizes were estimated with highest precision as indicated by the narrowest confidence intervals (Fig. 3). Among the biological controls, only products based on $B$. subtilis $(P=0.0251)$, and a treatment combining streptomycin and $P$. agglomerans-based products $(P=0.0124)$ had effect sizes greater than zero when tested under high disease intensity (Fig. 3B). By contrast, all the biocontrol products provided $\geq 50 \%$ disease control in studies where disease intensity was low. A similar result was obtained in the SAR-inducers category (Fig. 3C). Only Apogee, Messenger, and a treatment combining streptomycin and Vacciplant provided significant disease control over the nontreated control when tested under high disease intensity, but all products provided $\geq 50 \%$ disease control when tested under low disease intensity (Fig. 3C).

The effects of using products as combination treatments were only evaluated for the biological control and SAR-inducing products (Tables 2 and 3 ). In general, both biological controls and SAR-inducing products had lower $\bar{L}$ (and higher $\bar{C})(P<0.001)$ when tested in combination with streptomycin than when tested alone.

\section{DISCUSSION}

Although fire blight has been known for more than 200 years, and despite tremendous research efforts, effective control remains an elusive goal, and sporadic outbreaks with severe losses are common in most apple and pear production regions of the United States $(15,29,49)$. Not surprisingly, many studies have been carried out over the years to assess the efficacy of various products for control of fire blight. Most of these studies have focused on comparisons of disparate products within a test-year and location, and the results have generally been reported in PDMR, and its predecessors. There have been attempts to summarize the outcomes of these studies in several reviews over the years $(4,15,36,47,51)$. However, these reviews were not quantitative and although attempts were made to evaluate the performance of individual products across several studies the impact of study variance on the relative efficacy of individual products was not assessed. To the best of our knowledge, this is therefore the first fully quantitative review of the effects of various products evaluated for control of fire blight.

Several reasons could explain the paucity of quantitative synthesis of efficacy data on products tested for control of fire blight. The use of meta-analysis techniques is relatively new in

TABLE 3. Effect sizes (log of the response ratio), percent disease control, and corresponding test statistics for plant defense-activating compounds and antibioticdefense-activating compound combination products evaluated for fire blight control in the eastern United States based on reports published in Fungicide \& Nematicide Tests, Biological \& Cultural Tests, and Plant Disease Management Reports between 2000 and 2008

\begin{tabular}{|c|c|c|c|c|c|c|c|c|c|c|c|}
\hline \multirow[b]{2}{*}{ Product based on ${ }^{\mathrm{a}}$} & \multirow[b]{2}{*}{$K^{\mathrm{b}}$} & \multirow[b]{2}{*}{$R^{2 \mathrm{c}}$} & \multicolumn{6}{|c|}{ Effect size $^{\mathrm{d}}$} & \multicolumn{3}{|c|}{ Mean disease control (\%) } \\
\hline & & & $\bar{L}$ & $S E_{L}$ & $\mathrm{CI}_{L}$ & $\mathrm{CI}_{U}$ & $Z$ & $P$ & Control $(\bar{C})$ & $\mathrm{CI}_{L}$ & $\mathrm{CI}_{U}$ \\
\hline Streptomycin & 58 & 1.36 & -1.117 & 0.099 & -1.310 & -0.922 & -11.27 & $<0.0001$ & 67.27 & 60.23 & 73.05 \\
\hline Messenger & 13 & 3.20 & -0.298 & 0.084 & -0.462 & -0.134 & -3.57 & 0.0004 & 25.80 & 12.58 & 37.02 \\
\hline Vacciplant & 8 & 5.70 & -0.062 & 0.064 & -0.189 & 0.064 & -0.97 & 0.3322 & 6.05 & -6.60 & 17.20 \\
\hline Phosphites & 7 & 5.06 & -0.593 & 0.239 & -1.061 & -0.124 & -2.48 & 0.0132 & 38.49 & 11.66 & 65.35 \\
\hline Streptomycin + Actigard & 4 & 1.85 & -1.121 & 0.224 & -1.560 & -0.682 & -5.01 & $<0.0001$ & 67.39 & 49.41 & 78.98 \\
\hline
\end{tabular}

a The plus sign (+) indicates combination treatments in which one of the products was applied to experimental plots first followed by the other. Treatments consisting of the same pair of test products were combined regardless of the sequential order in which the two products were applied in the test (Streptomycin + Vacciplant or Streptomycin + Actigard).

${ }^{\mathrm{b}} K=$ total number of studies in the analysis in which the particular product or compound was tested. Only streptomycin, the standard treatment, was tested in all studies analyzed.

${ }^{c} R^{2}$ describes the inflation of the random effects confidence interval (CI) for the effect size compared with that from a fixed effects model (13).

d $\bar{L}=$ mean log-transformed response ratio for each treatment mean relative to the mean of the nontreated control; $S E_{L}=$ standard error of $\bar{L}$, lower $\left(\mathrm{CI}_{L}\right)$ and upper $\left(\mathrm{CI}_{U}\right)$ limits of the $95 \% \mathrm{CI}$ around $\bar{L}$; and $Z$ (standard normal) statistic from the meta-analysis. $P=$ probability value (significance of the effect size).

e Mean percent disease control $(\bar{C})$, lower $\left(\mathrm{CI}_{L}\right)$ and upper $\left(\mathrm{CI}_{U}\right)$ limits of the $95 \% \mathrm{CI}$ for $\bar{C}$. Values were calculated as $\bar{C}=(1-\bar{R}) \cdot 100$, where $\bar{R}$ is the mean response ratio or confidence limit estimate. Values of $\bar{R}$ and the confidence limit estimates were obtained by back-transforming $\bar{L}$ values and the confidence limits for $\bar{L}$.

${ }^{\mathrm{f}}$ The plant growth stimulating product vigorcal.

TABLE 4. Test statistics for the effects of moderator variables on effect sizes for three categories of products evaluated for fire blight control in the eastern United States based on a meta-analysis of reports published in Fungicide \& Nematicide Tests, Biological \& Cultural Tests, and Plant Disease Management Reports between 2000 and 2008

\begin{tabular}{|c|c|c|c|c|c|c|c|c|c|}
\hline \multirow[b]{2}{*}{ Moderator variable } & \multicolumn{3}{|c|}{ Antibiotics } & \multicolumn{3}{|c|}{ Biocontrol } & \multicolumn{3}{|c|}{ Plant defense-activating products } \\
\hline & df & $\chi^{2}$ & $P$ & $\mathrm{df}$ & $\chi^{2}$ & $P$ & $\mathrm{df}$ & $\chi^{2}$ & $P$ \\
\hline Cultivar ${ }^{\mathrm{a}}$ & 11 & 41.45 & $<0.0001$ & 9 & 197.06 & $<0.0001$ & 10 & 45.32 & $<0.0001$ \\
\hline State $^{c}$ & 6 & 122.77 & $<0.0001$ & 5 & 54.30 & $<0.0001$ & 6 & 71.44 & $<0.0001$ \\
\hline
\end{tabular}

${ }^{a}$ Cultivars included: Crispin, Fuji, Gala, Ginger Gold, Golden Delicious, Idared, Jonathan, Nittany, Pink Lady, Red Delicious, Rome Beauty, Royal Empire, and York Imperial.

${ }^{\mathrm{b}}$ Whether or not the product was tested as a combination treatment with another product (e.g., antibiotic followed by biological control). There were not sufficient data where antibiotics were tested in combination with other products to allow for the moderator effect test.

c The states included were Georgia, Massachusetts, Michigan, New York, North Carolina, Pennsylvania, and Virginia. 
phytopathological literature with most studies having been published in the last 5 years $(21,25,31-34,41,43)$. Perhaps a more important impediment, however, is the fact that most product efficacy reports in the databases we searched do not provide an explicit estimate of within-study variance, a component of any meta-analysis. Most studies in these data bases also do not report actual LSD or $P$ values either from which the within-study variance can be calculated (20). Instead, they indicate mean separations based on one of many multiple-comparison tests at a specified $P$ value, most commonly at 0.05 . Without an estimate of within-study variance, these studies would normally be deemed unsuitable for a meta-analysis $(3,20)$. To address this problem, we developed and tested a method for estimating within-study variance for studies in which a significant mean separation was indicated. Our results show that this method is highly accurate based on Lin's concordance analysis (18) of 35 calibration studies for which raw data were available. This estimation method performed best when at least two mean separations were available. Where only one separation occurs, as is common when all treatment means are different from the control but not from each other, the method may not provide an accurate estimate of LSD. Estimates from such studies should be assessed to determine if they deviate significantly from the predictions provided by the more precise estimates.

Among the three product category groups, the antibiotics are generally considered the most effective $(29,36,51)$, while the performance of the biological controls and the plant defense activators can be highly variable $(16,36,47,51)$. Even among the antibiotics and within a single product, significant variations occur between studies in the efficacy of fire blight control $(26,36$, 51,57). We used a multivariate random effects meta-analysis to determine the overall efficacy and heterogeneity of the products in these three broad categories. Because of the disparate nature of the studies (e.g., different investigators in many locations and years, and differences in the number and types of products being evaluated), we felt that the assumption of a common effect, central to a fixed-effects meta-analysis $(3,48,55)$, could not be justified. Indeed, our assessment of among-study variability based on the $R^{2}$ statistics (13) indicated highly significant (smallest $R^{2}$ value $=1.4$ for 58 studies) statistical heterogeneity. Our results indicate the following: (i) overall, the antibiotics were indeed the most efficacious products against fire blight, providing between 60 and $70 \%$ mean disease control; (ii) when applied alone, most biological control products had only a modest efficacy with between 20 and 32\% mean disease control; (iii) with the exception of pro-hexadion calcium (Apogee), most products specifically labeled as SAR-inducers were not very effective against fire blight, with mean disease control $<25 \%$; and (iv) the efficacy of most products was low and inconsistent at high fire blight severity.

Several observations can be drawn for the meta-analysis of antibiotics. Firstly, among the experimental antibiotics the overall mean effect sizes were very similar (59.8 to $61.7 \%$ ) but lower than that of streptomycin, the current standard (70\%). Although a direct comparison with the values reported in previous nonquantitative reviews is not possible, the ranking of antibiotics efficacy in this meta-analysis is consistent with the general observations from these reviews about the performance of specific antibiotics $(36,51)$. A second observation is that estimates of the mean effect sizes (and therefore mean disease control) for streptomycin from the three product-category meta-analyses $(69.8,68.9$, and $67.3 \%$ for antibiotics, biological control, and plant defense activators meta-analyses, respectively) were similar but not exactly equal. This result occurs because in a multivariate meta-analysis data from all treatments and studies contribute to the estimation of all mean effect sizes for each treatment $(3,40,55)$. This is due to the between-study correlation of effect sizes and the fact that the between-study variance affects the estimates of all means. Because the number of studies in each analysis, and hence the values of responses contributing to the streptomycin effect size, was not exactly the same in the three meta-analyses, the differences in the estimated effect size were therefore not unexpected. Paul et al. (33) arrived at a similar result when comparing effect sizes of tebuconazole estimated from the same data set based on a univariate (32) and multivariate random effects meta-analyses (33).

The third observation is that the estimated mean percent control for streptomycin $(70 \%)$ was around the lower end of that reported in a previous nonquantitative review by Psallidas and Tsiantos (36). A value of $70 \%$ would have been ranked only as moderate by van der Zwet and Kiel (51), which is below two of their other categories (good, 76 to $89 \%$ control; and excellent $\geq 90 \%$ control). Differences in results are not surprising because in a metaanalysis the study results are properly weighted based on their

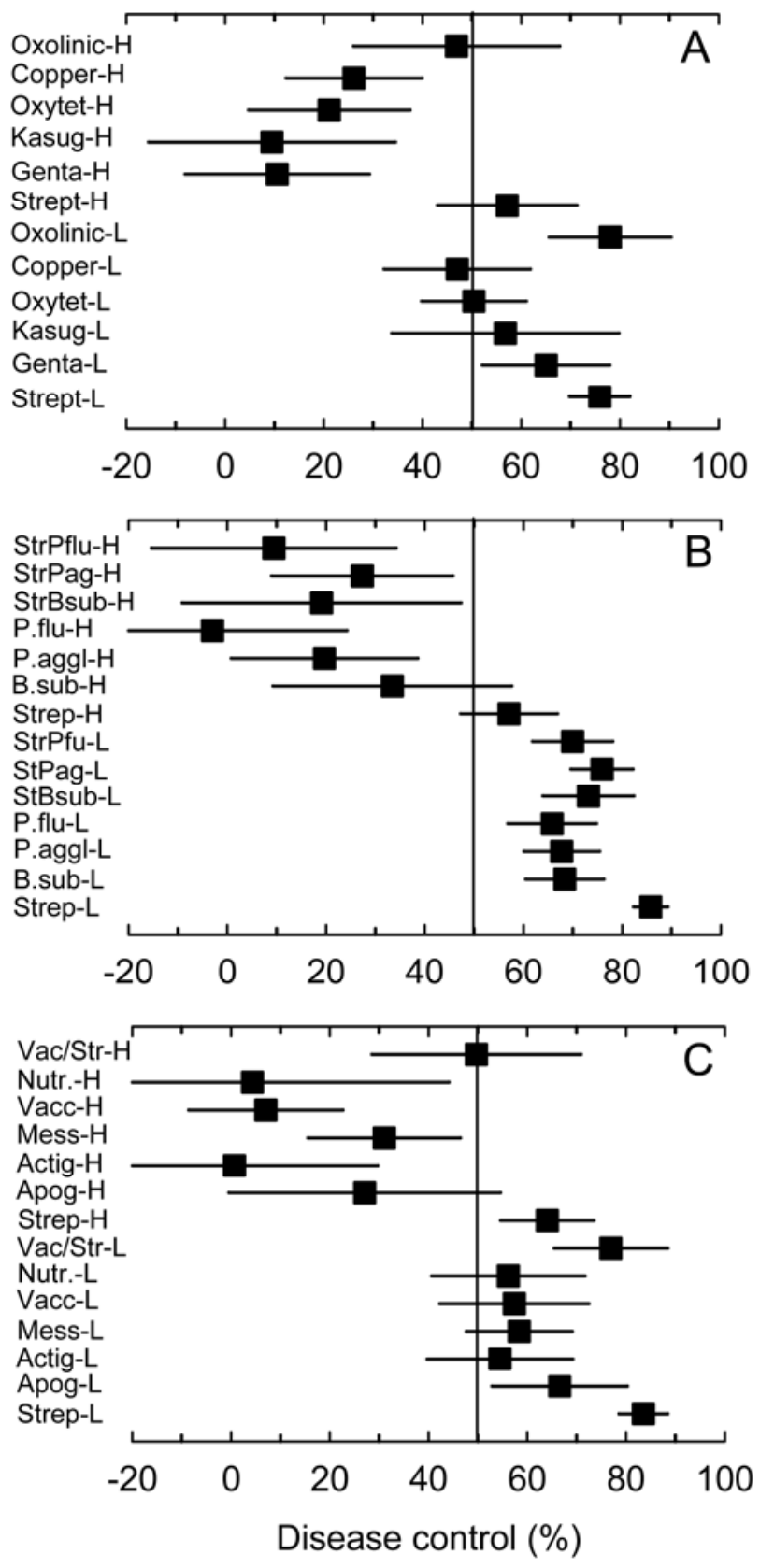

Fig. 3. A, Effects of antibiotics, $\mathbf{B}$, biological control, and $\mathbf{C}$, systemic acquired resistance-inducing products evaluated for fire blight control under low (L; fire blight severity in nontreated control $<65 \%)$ and high $(\mathrm{H}$; fire blight severity in nontreated control $\geq 65 \%$ ) disease intensity conditions in eastern United States from 1999 to 2007. Values are mean effect sizes and 95\% confidence limits transformed to percent disease control. 
variability or precision (3), whereas in a nonquantitative review the within-study variance is not considered. That is, the mean of $70 \%$ control is therefore a weighted average of effect sizes over the full range of disease intensity levels.

The average effect sizes estimated for biocontrol products ranged from about 15 to $32 \%$ control. These levels of disease control are much lower than the 40 to $60 \%$ reported for some specific studies $P$. fluorescens-based products $(16,17,19)$, or the 50 to $80 \%$ reported for $P$. agglomerans products $(16,17)$, also in specific studies. However, the estimates found here are very close to the averages reported for the biological controls in the eastern United States in separate nonquantitative reviews, in which disease control averaged 9 to $36 \%$ (47) and 11 to $35 \%$ (4). It is reasonable to suggest that significant differences in results for the eastern and western United States are an outcome of disparate environmental conditions between the two apple production regions. Nonetheless, perhaps a more plausible explanation involves differences in testing methodology. Most of the studies evaluating the efficacy of biological controls in the western United States relied on natural E. amylovora inoculum to initiate disease. By contrast, most of the studies used in the present meta-analysis, as well as those reviewed by Cooley (4) and Sundin et al. (47), used a blossom inoculation procedure.

Interestingly, products based on $P$. agglomerans did not perform as well as those based on B. subtilis, whose estimated mean disease control (32\%) was the highest among the biological controls. In contrast, Johnson and Stockwell (16) and Stockwell and Stack (46), found that $P$. agglomerans was more effective in western United States in studies utilizing bee-mediated inoculations of blossom that more closely resemble natural E. amylovora spread and inoculums levels in orchards $(16,46)$. Several factors may explain this disparity in results, including the differences in inoculation methods. It is possible that in the presence of high densities of the pathogen (E. amylovora), B. subtilis can establish and multiply on blossoms better than $P$. agglomerans (formerly $E$. herbicola), which is closely related to E. amylovora (7). It is also likely that differences in the environmental factors between the eastern and western U.S. apple growing regions affect flower ecology which may have differentially impacted product efficacy. Although both $B$. subtilis and $P$. agglomerans exhibit antibiosis and competitive exclusion as modes of action on blossoms $(38,44,45)$, the impact of environmental factors on the expression of these mechanisms by the two biocontrol agents has not been quantified. Furthermore, regional differences may also exist based on environmental influences on the development of E. amylovora.

Except for prohexadione calcium, products specifically labeled as plant defense activators had very low estimated mean effect sizes and very high between-study variability when tested as sole products. Strong evidence for among-study variability for these treatments was indicated by the high $R^{2}$ statistic values. Estimates of mean percent disease control were only 26, 17, and $6 \%$ for Messenger, Actigard, and Vacciplant, respectively, and Vacciplant did not offer significant fire blight reduction relative to the nontreated control. These mean values are lower than those reported in a few individual studies $(1,10,22)$. For example, $>57 \%$ fire blight reduction has been reported for Actigard in naturally occurring infections (22), and for Messenger in some studies with inoculated blossoms (1). Overall, the products specifically labeled as SAR-inducers have previously been reported to have variable results $(4,29)$. Given the risks associated with fire blight, it is unlikely that most of the plant defense-activating products will become widely integrated into programs for commercial apple and pear production. The results for Apogee, which had the highest effect size and the lowest $R^{2}$ statistic (Table 3), indicate that this product performed consistently and support its use in an integrated program for fire blight management.

Two hypotheses consistent with the current knowledge of flower biology can be advanced that may explain the relatively poor performance of the plant defense-activating compounds. Flowers, the site infection of E. amylovora, in general may not respond well to SAR inducers probably because from an evolutionary standpoint, flowers are so critical to plant reproduction that an innate, nontransitory, defense mechanism is required for their defense (27). Alternatively, plants may not invest resources in a defense activation pathway in transient organs such as flowers which abscise within a few days after pollination (27). Effective SAR-products generally need to be applied multiple times before the arrival of the pathogen $(9,28,50)$ suggesting that the pathways involved are unlikely to be present in transient floral tissue. On the other hand, the induction of plant defense mechanisms such as the SAR is complex, involving the activity of multiple genes $(9,50,54)$, which would appear to support the second hypothesis. Further research in this area is clearly needed.

A key advantage of the meta-analysis presented here over previous qualitative reviews $(4,36,47,51)$ was the ability to evaluate the effects of moderator variables on the mean effect sizes for the various products. All moderator variables analyzed were found to significantly influence the performance of the different products but the effects of disease intensity in the trial were the most pronounced. Regardless of the product category, the effect sizes were lower and more variable when products were tested under high rather than low disease intensity (Fig. 3). Except for oxolinic acid, other experimental antibiotics had significantly lower disease control than streptomycin when tested at high disease pressure, and for most of the biological control and plant defenseactivating products, the effect sizes were not significantly different from zero under high disease intensity. A surprising high degree of consistency was noted for the mean effect sizes for the different biocontrol products when tested under low disease intensity. These outcomes indicated that the low estimates of mean effect sizes obtained in the absence of a moderator variable were mainly due to the poorer performance of the products under high disease intensity. Interestingly, streptomycin, the most efficacious product for control of fire blight, also had the least difference in mean effect size when evaluated under different disease intensity conditions. These results suggest that product evaluations carried out under high disease intensity are a better indicator of product efficacy and consistency for control of fire blight.

The observation that disease intensity significantly affects the efficacy of biocontrol products is in contrast with that of Ojiambo and Scherm (31). In a meta-analysis of factors influencing the performance of biocontrol products across a very wide range of crop-pathogen combinations, these authors concluded that the efficacy of biological controls was similar under conditions of low, moderate, or high disease intensity (31). However, their results were not specific to fire blight and they did not include many of the studies that were in our data set. Our results on the effects of disease intensity on product performance concur with the outcomes of many studies assessing the effectiveness of biocontrol agents $(16,19,26,37,46)$, and SAR-inducing products $(9,54)$. In general, high disease intensity typical in fire blight trials in which blossoms are inoculated with E. amylovora tends to overwhelm biological controls $(16,46)$.

The performance of both the biological controls and plant defense-activating compounds improved significantly when these products were evaluated in a combination with the antibiotic streptomycin. The mean percent disease control for biological controls evaluated with streptomycin (42 to 54\%) were between those for streptomycin used alone $(69 \%)$ and the sole biocontrol products $(15$ to $32 \%)$. It is reasonable to speculate that the increased efficacy of the biological controls and defense-activating compounds resulted from the effects of streptomycin. Indeed, such outcomes have been documented in individual trials featuring different biocontrol agent-streptomycin combinations $(16,46$, $56,58)$. Because the effect sizes of these combination treatments 
did not exceed that of streptomycin alone, we conclude that synergistic interactions (sensu Gisi, 1996 [8]) do not occur. Although it is clear that based on our results, one could not justify the cost of using both streptomycin and a biocontrol agent (or a plant defense activator), most of these biological controls and plant defense activators were not intended to replace, but rather to complement streptomycin, possibly giving other benefits even when percent control is not affected. Biocontrol products may, for instance, offer additional benefits that cannot be quantified in the current meta-analysis, such as slowing the development resistance to streptomycin in populations of E. amylovora (46). Where resistance to streptomycin is a problem, the other products considered here are intended to replace the antibiotic. Based on these results, the currently available products will not provide control equal to that from streptomycin.

The significant effects of cultivar and state as moderator variables indicate an influence of environmental and host factors in disease development and, by extension, product efficacy. These results correspond with those of several meta-analyses examining the performance of fungicides for control of wheat scab $(F u$ sarium graminearum), in which fungicide efficacy was significantly higher for spring wheat than for soft winter wheat $(32,33)$. For biological controls in particular, these results also emphasize a need for testing the biocontrol agents in multiple locations since other microorganisms in the environment may affect the performance of the products.

Taken together, our results indicate that despite an extensive search for effective products for control of fire blight, none of the ones evaluated so far is as effective as the antibiotic streptomycin, the current standard. The need for new products and for strategies to mitigate the risk of resistance development towards streptomycin in the eastern United States therefore cannot be overstated. This study also illustrates the inconsistency inherent in efficacy of biocontrol products and plant defense-activating products in general. Given the risk associated with fire blight and the efficacy of the products, wide-scale use of biocontrol and plant defense-activating products in the eastern United States is likely to remain low. Any new products should also be subjected to more rigorous evaluations over multiple years and locations, and the results should then be combined in a meta-analysis following procedures such as those outlined here. In this regard, the method developed here for estimating the within-study variance should prove valuable and allow inclusion of studies that do not directly provide this statistic.

\section{ACKNOWLEDGMENTS}

This research was funded by the State Horticultural Association of Pennsylvania (SHAP). We thank D. Scotton for valuable technical support. Products and companies are mentioned solely for research and educational purposes and are not recommended over similar products.

\section{LITERATURE CITED}

1. Aldwinckle, H. S., Bhashkara Reddy, M. V., and Norelli, J. L. 2002. Evaluation of control of fire blight infection of apple blossoms and shoots with SAR inducers, biological agents, a growth regulator, copper compounds, and other materials. Acta Hortic. 590:325-331.

2. Billing, E. 2000. Fire blight risk assessment systems and models. Pages 293-318 in: Fire Blight: The Disease and Its Causative Agent, Erwinia amylovora. J. L. Vanneste, ed. CAB International, Wallingford, UK.

3. Borenstein, M., Hedges, L. V., Higgins, J. T., and Rothstein, H. R. 2009. Introduction to Meta-Analysis. John Wiley \& Sons, Ltd., West Sussex, UK.

4. Cooley, D. R. 2006. Are biological controls and resistance activators viable alternatives to streptomycin? Fruit Notes 71:12-16.

5. Costa, G., Andreotti, C., Bucchi, F., Sabatini, E., Bazzi, C., Malaguti, S., and Rademacher, W. 2001. Prohexadione-Ca (Apogee): Growth regulation and reduced fire blight in pear. Hortscience 36:931-933.

6. Dewdney, M. M., Biggs, A. R., and Turechek, W. W. 2007. A statistical comparison of the blossom blight forecasts of MARYBLYT and
Cougarblight with receiver operating characteristic curve analysis. Phytopathology 97:1164-1176.

7. Gavini, F., Mergaert, J., Beji, A., Mielcarek, C., Izard, D., Kesters, K., and De Ley, J. 1989. Transfer of Enterobacter agglomerans (Beijerinck 1888) Ewing and Fife 1972 to Pantoea gen. nov. as Pantoea agglomerans comb. nov. and description of Pantoea dispersa sp. nov. Int. J. Syst. Bacteriol. 39:337-345.

8. Gisi, U. 1996. Synergistic interaction of fungicides in mixtures. Phytopathology 86:1273-1279.

9. Gozzo, F. 2003. Systemic acquired resistance in crop protection: From nature to a chemical approach. J. Agric. Food Chem. 51:4487-4503.

10. Günen, Y., Özdemir, N., Günen, E., Türküsay, H., Tosun, N., and Saygıll, H. 2006. Efficacies of plant activators in control of fire blight of pear in Turkey. Acta Hortic. 704:259-263.

11. Hedges, L. V., Gurevitch, J., and Curtis, P. S. 1999. The meta-analysis of response ratios in experimental ecology. Ecology 80:1150-1156.

12. Hedges, L. V., and Olkin, I. 1980. Vote-counting methods in research synthesis. Psychol. Bull. 88:359-369.

13. Higgins, J. P. T., and Thompson, S. G. 2002. Quantifying heterogeneity in a meta-analysis. Stat. Med. 21:1539-1588.

14. Hunter, J. E., and Schmidt, F. L. 2004. Methods of Meta-Analysis: Correcting Error and Bias in Research Findings. 2nd ed. Sage Publications Inc., Thousand Oaks, CA.

15. Johnson, K. B., and Stockwell, V. O. 1998. Management of fire blight: A case study in microbial ecology. Annu. Rev. Phytopathol. 36:227-248.

16. Johnson, K. B., and Stockwell, V. O. 2000. Biological control. Pages 319337 in: Fire Blight: The Disease and Its Causative Agent, Erwinia amylovora. J. Vanneste, ed. CAB International, Wallingford, UK.

17. Johnson, K. B., Stockwell, V. O., McLaughlin, M. J., Sugar, D., Lopper, J. E., and Roberts, R. G. 1993. Effect of bacterial antagonists on establishment of honey bee-dispersed Erwinia amylovora in pear blossoms and on fire blight control. Phytopathology 83:995-1002.

18. Lin, L. I.-K. 1989. A concordance correlation coefficient to evaluate reproducibility. Biometrics 45:255-268.

19. Lindow, S. E., McGourty, G., and Elkins, R. 1996. Interactions of antibiotics with Pseudomonas fluorescens A506 in the control of fire blight and frost injury in pear. Phytopathology 86:841-848.

20. Lipsey, M. W., and Wilson, D. B. 2001. Practical Meta-Analysis. SAGE Publications, Inc., Thousand Oaks, CA.

21. Madden, L. V., and Paul, P. A. 2011. Meta-analysis for evidence synthesis in plant pathology: An overview. Phytopathology 101:16-30.

22. Maxson-Stein, K., He, S.-Y., Hammerschmidt, R., and Jones, A. L. 2002. Effect of treating apple trees with acibenzolar-S-methyl on fire blight and expression of pathogenesis-related protein genes. Plant Dis. 86:785-790.

23. McManus, P. S., and Jones, A. L. 1994. Epidemiology and genetic analysis of streptomycin-resistant Erwinia amylovora from Michigan and evaluation of oxytetracycline for control. Phytopathology 84:627-633.

24. McManus, P. S., Stockwell, V. O., Sundin, G. W., and Jones, A. L. 2002. Antibiotic use in plant agriculture. Annu. Rev. Phytopathol. 40:443-465.

25. Ngugi, H. K., Esker, P. D., and Scherm, H. 2011. Meta-analysis to determine the effects of plant disease management measures: Review and case studies on soybean and apple. Phytopathology 101:31-41.

26. Ngugi, H. K., Halbrendt, N. O., and Travis, J. W. 2009. Evaluation of antibiotics and biological control products for control of fire blight, 2008. Plant Dis. Manage. Rep. 3:PF001.

27. Ngugi, H. K., and Scherm, H. 2006. Biology of flower-infecting fungi. Ann. Rev. Phytopathol. 44:261-282.

28. Ngugi, H. K., Singh, D. K., Lehman, B. L., Travis, J. W., and McNellis, T. W. 2008. Explaining the association between apple tree stress and resistance to the fire blight bacterium Erwinia amylovora. Phytopathology (Abstr.) 98(suppl.):S113.

29. Norelli, J. L., Jones, A. L., and Aldwinckle, H. S. 2003. Fire blight management in the twenty-first century-using new technologies that enhance host resistance in apple. Plant Dis. 87:756-765.

30. Norelli, J. L., and Miller, S. S. 2004. Effect of prohexadione-calcium dose level on shoot growth and fire blight in young apple trees. Plant Dis. 88:1099-1106.

31. Ojiambo, P. S., and Scherm, H. 2006. Biological and application-oriented factors influencing plant disease suppression by biological control: A meta-analytical review. Phytopathology 96:1168-1174.

32. Paul, P. A., Lipps, P. E., Hershman, D. E., McMullen, M. P., Draper, M. A., and Madden, L. V. 2007. A quantitative review of tebuconazole effect on Fusarium head blight and deoxynivalenol content in wheat. Phytopathology 97:211-220.

33. Paul, P. A., Lipps, P. E., Hershman, D. E., McMullen, M. P., Draper, M. A., and Madden, L. V. 2008. Efficacy of triazole-based fungicides for Fusarium head blight and deoxynivalenol control in wheat: A multivariate meta-analysis. Phytopathology 98:999-1011.

34. Paul, P. A., Lipps, P. E., and Madden, L. V. 2006. Meta-analysis of regression coefficients for the relationship between Fusarium head blight 
and deoxynivalenol content of wheat. Phytopathology 96:951-961.

35. Pierstorff, A. L., and Lamb, H. N. 1934. The honeybee in relation to the overwintering and primary spread of the fire-blight organism. Phytopathology 24:1347-1375.

36. Psallidas, P. G., and Tsiantos, J. 2000. Chemical control of fire blight. Pages 199-234 in: Fire Blight: The Disease and Its Causative Agent, Erwinia amylovora. J. Vanneste, ed. CAB International, Wallingford, UK.

37. Pusey, P. L. 2002. Biological control agents for fire blight of apple compared under conditions limiting natural dispersal. Plant Dis. 86:639644.

38. Pusey, P. L., Stockwell, V. O., and Rudell, D. R. 2008. Antibiosis and acidification by Pantoea agglomerans strain E325 may contribute to suppression of Erwinia amylovora. Phytopathology 98:1136-1143.

39. Ramsey, F., and Schafer, D. 1997. The Statistical Sleuth: A Course in Methods of Data Analysis. Duxbury Press, Belmont, CA.

40. Riley, R. D., Abrams, K. R., Lambert, P. C., Sutton, A. J., and Thompson, J. R. 2007. An evaluation of bivariate random-effects meta-analysis for the joint synthesis of two correlated outcomes. Stat. Med. 26:78-97.

41. Rosenberg, M. S., Garrett, K. A., Su, Z., and Bowden, R. L. 2004. Metaanalysis in plant pathology: Synthesizing research results. Phytopathology 94:1013-1017.

42. Russo, N. L., Burr, T. J., Breth, D. I., and Aldwinckle, H. S. 2008. Isolation of streptomycin resistant isolates of Erwinia amylovora in New York. Plant Dis. 92:714-718.

43. Scherm, H., Christiano, R. S. C., Esker, P. D., Del Pont, E. M., and Godoy, C. V. 2009. Quantitative review of fungicide efficacy trials for managing soybean rust in Brazil. Crop Prot. 28:774-782.

44. Scherm, H., Ngugi, H. K., Savelle, A. T., and Edwards, J. R. 2004. Biological control of infection of blueberry flowers caused by Monilinia vaccinii-corymbosi. Biol. Control 29:199-206.

45. Stockwell, V. O., Johnson, K. B., Sugar, D., and Loper, J. E. 2002. Antibiosis contributes to biological control of fire blight by Pantoea agglomerans strain Eh252 in orchards. Phytopathology 92:1202-1209.

46. Stockwell, V. O., and Stack, J. P. 2007. Using Pseudomonas spp. for integrated biological control. Phytopathology 97:244-249.

47. Sundin, G. W., Werner, N. A., Yoder, K. S., and Aldwinckle, H. S. 2009.
Field evaluation of biological control of fire blight in the eastern United States. Plant Dis. 93:386-394.

48. Sutton, A. J., and Abrams, K. R. 2001. Bayesian methods in meta-analysis and evidence synthesis. Stat. Methods Med. Res.10:277-303.

49. Thompson, S. V. 2000. Epidemiology of fire blight. Pages 9-36 in: Fire Blight: The Disease and Its Causative Agent, Erwinia amylovora. J. L. Vanneste, ed. CAB International, Wallingford, UK.

50. Vallad, G. E., and Goodman, R. M. 2004. Systemic acquired resistance and induced systemic resistance in conventional agriculture. Crop Sci. 44:1920-1934.

51. van der Zwet, T., and Kiel, H. L. 1979. Fire Blight: A Bacterial Disease of Rosaceous Plants. United States Department of Agriculture Handbook 510. Washington, DC.

52. van Houwelingen, H. C., Arends, L. R., and Stijnen, T. 2002. Advanced methods in meta-analysis: Multivariate approach and meta-regression. Stat. Med. 21:589-624.

53. Vanneste, J. L. 2000. What is fire blight? Who is Erwinia amylovora? How to control it? Pages 1-6 in: Fire Blight: The Disease and Its Causative Agent, Erwinia amylovora. J. L. Vanneste, ed. CAB International, Wallingford, UK.

54. Walters, D., Walsh, D., Newton, A., and Lyon, G. 2005. Induced resistance for plant disease control: Maximizing the efficacy of resistance elicitors. Phytopathology 95:1368-1373.

55. Whitehead, A. 2002. Meta-Analysis of Controlled Clinical Trials. John Wiley and Sons, West Sussex, England.

56. Yoder, K. S., Cochran, A. E., II, Royston, W. S., Jr., and Kilmer, S. W. 2007. Integrated biological and streptomycin treatments for fire blight control on 'Idared' apples, 2006. Plant Dis. Manage. Rep. 1:PF028.

57. Yoder, K. S., Cochran, A. E., II, Royston, W. S., Jr., and Kilmer, S. W. 2008. Test of Agri-Fos/Pentra-Bark trunk treatments and foliar antibiotic applications for blossom blight control, 2007. Plant Dis. Manage. Rep. 2:PF022.

58. Yoder, K. S., Cochran, A. E., II, Royston, W. S., Jr., and Kilmer, S. W. 2009. Test of antibiotics and SAR candidates for blossom blight control on Golden Delicious and Rome Beauty apples, 2008. Plant Dis. Manage. Rep. 3:PF008 